\title{
Smart Oxygen Membrane
}

\author{
Vladimir Zyryanov
}

Institute of Solid State Chemistry and Mechanochemistry, Siberian Branch of Russian Academy of Sciences, 630090 Novosibirsk, Kutateladze 18, Russian Federation

\begin{abstract}
Oxygen selective membrane based on $\delta-\mathrm{Bi}_{2} \mathrm{O}_{3} / \mathrm{Ag}$ cermet has maximum potential in separating oxygen from air. However, the achieved oxygen flow is inferior to high-temperature membranes. The paper proposes a new approach to creating a smart oxygen membrane with a selective layer from a nanocomposite with a complex architecture, operating at intermediate temperatures $\left(\mathrm{T}_{\mathrm{op}} \sim 550-600^{\circ} \mathrm{C}\right)$. At the stage of obtaining nanopowders of membrane components, the potential and features of the mechanochemical ceramic method are taken into account. Mild conditions at the stage of consolidation by hot pressing are provided by the composition of the AgCu-matrix alloy. Achieving a gas-tight selective layer at the stage of reaching $\mathrm{T}_{\mathrm{op}}$ is ensured by dilatation of some components during the oxidation of copper alloys. The choice of $\mathrm{T}_{\text {op }}$ for the oxygen membrane is based on the possibility of regeneration while maintaining the nanoscale microstructure. New solutions allow the creation of stable thin membranes with a reduced cost, including due to the silver content near the percolation threshold.
\end{abstract}

\section{Introduction}

There are several types of oxygen selective membranes (OSM). Two of them are SOFC (solid oxide fuel cell) membranes made of solid electrolytes with deposited porous electrodes and CMR (catalytic membrane reactor) membranes made of mixed ionicelectronic conducting (MIEC) ceramics for the implementation of processes such as partial oxidation of methane. A huge number of publications have been published on these types of membranes, with no visible commercial success in the market. Oxygen flow through the membranes is provided by a significant difference in oxygen partial pressures due to the reducing gas. The third type is oxygen separators (OS) based on membranes made of MIEC materials - mainly complex oxides with the structure of perovskite or cermets $\delta-\mathrm{Bi}_{2} \mathrm{O}_{3} / \mathrm{Ag}$. The oxygen flow is generated by high air pressure, which can be reduced by using a sweep gas. In the case of a cermet membrane, the sweep gas must contain $\mathrm{O}_{2}$ because $\mathrm{Bi}_{2} \mathrm{O}_{3}$ is unstable in a reducing atmosphere. Published works on OS are disproportionately small, and on cermet membranes, their number does not exceed 10 [1-4]. In the United States, oxygen transporting membrane technology based on MIEC complex perovskites has been developed for coal combustion in pure oxygen (oxy-fuel combustion) for the subsequent capture and storage of $\mathrm{CO}_{2}$. Cermet membranes, composed of the best ionic and electronic conductors, have the potential to maximize air separation efficiency. Weak attention to them is associated with the rapid degradation of functional properties and the instability of 
bismuth oxide in a reducing atmosphere. Testing stabilized $\delta-\mathrm{Bi}_{2} \mathrm{O}_{3}$ with the fluorite structure showed a rapid deterioration of conducting properties due to the ordering of oxygen vacancies with subsequent phase transformation into stable dielectric phases. Doping with highly charged cations improves the kinetic stabilization of the fluorite structure [4]. With decreasing membrane thickness, the oxygen flux is limited by oxygen exchange reactions at the contact line of three phases $\delta$ - $\mathrm{Bi}_{2} \mathrm{O}_{3}$-Ag-gas $[1,3]$. The nanoscale structure of cermet, which can be obtained by the mechanochemical ceramic method [2], should provide a high rate of exchange reactions. However, in this case, the rate of total degradation also increases. The acceleration of the phase degradation of $\delta-\mathrm{Bi}_{2} \mathrm{O}_{3}$ is associated with incorporating silver into the fluorite lattice with the local formation of additional oxygen vacancies, which promote the ordering of oxygen vacancies [4]. Mechanochemical nanopowders of oxide ceramics contain a free volume of up to $9 \%$ in the form of vacancy defects, which is five orders of magnitude higher than the equilibrium content of Schottky defects [5]. The high concentration of cation vacancies in the fluorite structure favors the incorporation of $\mathrm{Ag}^{+}$. The deposition of a $\mathrm{Pd}(\mathrm{Pt})$ catalyst on the cermet surface sharply accelerates the degradation processes, including the recrystallization and segregation of silver. It can be assumed that a highly mobile state $\mathrm{Ag}-\mathrm{O}-\mathrm{Ag} \leftrightarrow \mathrm{Ag}^{+}-\mathrm{O}^{2-}-\mathrm{Ag}^{+}$ is formed on the silver surface. Taking into account degradation processes [4], we obtained gas-tight nanocermet with an interpenetrating structure 608- $\mathrm{Bi}_{2} \mathrm{O}_{3} / 40(60 \mathrm{Ag} @ 40 \mathrm{P})$ from annealed at $400{ }^{\circ} \mathrm{C} \delta-\mathrm{Bi}_{2} \mathrm{O}_{3}$ nanopowder by hot pressing at $350{ }^{\circ} \mathrm{C}$ and a pressure of $1 \mathrm{GPa}$. Prepared nanocermet successfully passed the long-term test for 500 hours at $500{ }^{\circ} \mathrm{C}$ with a significant reduction in silver segregation. Instead of silver, the core-shell nanocomposite $\mathrm{Ag} @ \mathrm{P}$ (where $\mathrm{P}$ is a perovskite $\mathrm{La}_{0.5} \mathrm{Y}_{0.3} \mathrm{Pr}_{0.2} \mathrm{Cr}_{0.5} \mathrm{Fe}_{0.3} \mathrm{Mn}_{0.2} \mathrm{O}_{3}$ with a high electronic conductivity [4] and good wettability to $\mathrm{Ag}$ ) was used. A solid electrolyte of composition $\mathrm{Bi}_{0.76} \mathrm{Y}_{0.06} \mathrm{Er}_{0.08} \mathrm{~Tb}_{0.08} \mathrm{~W}_{0.02} \mathrm{O}_{1.5+\mathrm{x}}$ with a high conductivity and good kinetic stabilization of fluorite structure was found. The obtained nanocermet showed the fundamental feasibility of intermediate temperature (IT) oxygen membranes. However, control samples prepared with small deviations of parameters display degradation. For example, the porosity of cermet after the consolidation of more than $5 \%$ promotes degradation because it facilitates the recrystallization and deformation of $\delta-\mathrm{Bi}_{2} \mathrm{O}_{3}$ grains associated with the ordering of oxygen vacancies. Hot pressing parameters are too difficult to commercialize the technology. Further optimization of the parameters for materials, roadmap and architecture are required to fabricate an effective membrane. The challenge is to develop an IT smart OSM for accommodation at all stages of the life cycle.

\section{Experimental}

Reagent grade powders of metal oxides and metals with a purity $>99.9 \%$ from Reachim, Russia, and other manufacturers were used. Nanopowders were obtained by the solid state method using mechanical activation (MA) in the high-energy planetary mill AGO-2, Russia. MA of the powders was carried out in the most intensive mode $60 \mathrm{~g}$ with stainless steel balls $4 \mathrm{~mm}$ in diameter. The mass ratio of material and balls was $(20-30 \mathrm{~g}) / 200 \mathrm{~g}$, time of milling 5-30 $\mathrm{min}$ (supplied energy $\mathrm{E}_{\mathrm{s}}=15-100 \mathrm{MJ} / \mathrm{kg}$ ). A standard procedure of milling for ceramic powders was used [5]. According to this procedure, continuous mechanical treatment of ceramic powder was $60 \mathrm{~s}$ in a pre-coated steel medium with the same material. After stopping the mill, the powders and balls were remixed to avoid the accumulation of material in the dead zone of the milling jars. The operations of milling and firing at 500$800^{\circ} \mathrm{C}$ were repeated three times for ceramics. $\mathrm{CuMn}_{2}$ alloy with $\mathrm{FCC}$ structure was obtained by MA of metal powders after firing at $900^{\circ} \mathrm{C}$ in nitrogen atmosphere with subsequent milling of sintered powder. The used procedure provides simultaneously high powder uniformity and drastically reduced iron contamination of materials. The 
characterization of powders and materials was carried out by a combination of methods. XRD data were collected on a D8-Advance (Bruker, Germany) using $\mathrm{CuK} \alpha$-radiation. The full-profile Rietveld analysis of the obtained data was done using TOPAS and PowderCell2.1 programs. SEM studies with EDS were carried out on the microscope TM-1000 (Hitachi, Japan). The selection of ceramic fillers was done after studies of conducting properties of sintered at $800{ }^{\circ} \mathrm{C}$ ceramics by the 4-electrode scheme in installation IPU-1, Russia). Sintering of MA ceramic powders after pressing at $200 \mathrm{MPa}$ was carried out at relatively low temperatures in order to prevent phase transformations and preserve the nanostructure.

\section{Results and discussion}

Designed to implement the principles of a smart OSM, the general architecture consists of a support made of modified stainless steel grid, filled by ceramic composite, a gas-tight nanocermet layer $10 \mu \mathrm{m}$ thick, porous protective, and catalytic layers 1-2 $\mu \mathrm{m}$ thick [4]. For improving the kinetic stability of $\delta-\mathrm{Bi}_{2} \mathrm{O}_{3}$ with fluorite structure $(\mathrm{F})$ we study conducting properties and long-term stability of solid electrolytes family on the base $\mathrm{Bi}_{0.8} \mathrm{Dy}_{0.12} \mathrm{Er}_{0.08} \mathrm{O}_{1.5}$, doped by $2 \%$ molar of $\mathrm{W}^{6+}, \mathrm{Ta}^{5+}, \mathrm{Me}^{4+}$ (including a mix of cations). Doped by $\mathrm{W}^{6+}$ samples display relatively good phase stability and conductivity. The structure of the key component of the selective layer in a smart OSM, Ag-based nanocomposite, is shown in Fig. 1.
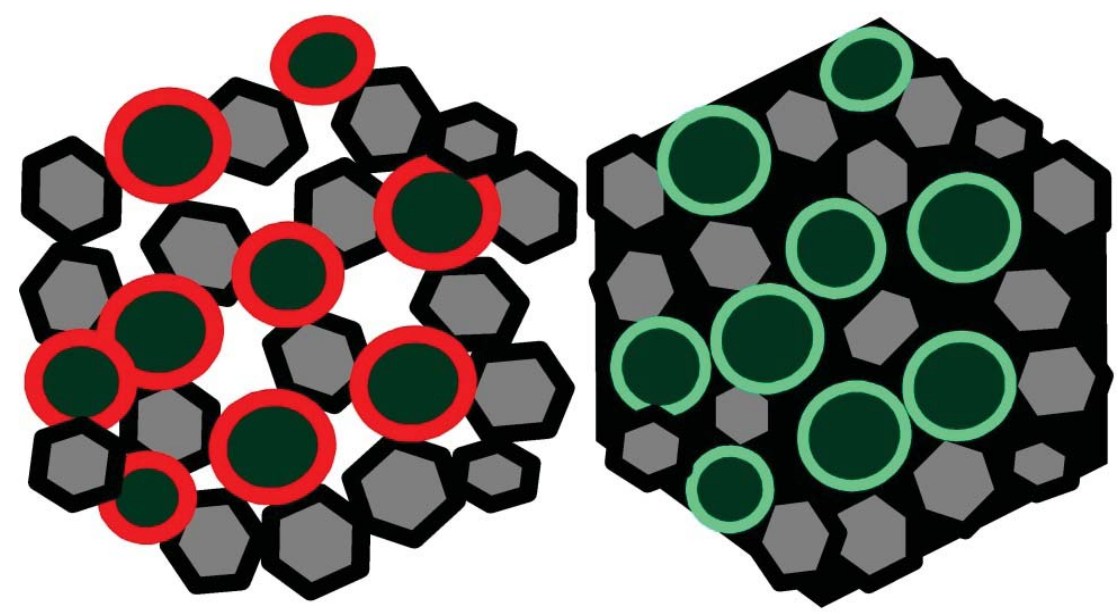

Fig. 1. Schematic representation of Ag-based nanocomposite after the consolidation of mixed nanopowders by hot pressing (left), and after oxidation and sintering at $\mathrm{T}_{\mathrm{op}}$ (right). Black - Ag-based matrix, red $-\mathrm{CuMn}_{2}$.

Instead of Ag, we propose to use a two-level nanocomposite of «core-shell» structure with metal-matrix alloy $\mathrm{Ag}_{0.7} \mathrm{Cu}_{0.3} @(\mathrm{P})\left(\mathrm{CuMn}_{2} @ \mathrm{~S}\right)$, where $\mathrm{P}$ selected perovskite ceramics $\mathrm{La}_{0.7} \mathrm{Y}_{0.3} \mathrm{Co}_{0.5} \mathrm{Fe}_{0.3} \mathrm{Mn}_{0.2} \mathrm{O}_{3}$ with high conducting properties [6] (Fig. 2), $\mathrm{S}$ - spinel $\mathrm{CuMn}_{2} \mathrm{O}_{4}$. The general formula of cermet with stabilized fluorite for the selective layer of membrane can be presented in the form 60F/40[A@(P)(M@S)]. At a ratio of 60:40, the interpenetrating structure of composites is formed reliably [1,4]. Metal-matrix alloy A with 
closed to optimal composition $\mathrm{Ag}_{0.7} \mathrm{Cu}_{0.3}$ has a melting point $\mathrm{T}_{\mathrm{m}}=820^{\circ} \mathrm{C}(140 \mathrm{~K}$ lower than silver). $\mathrm{M}=\mathrm{CuMn}_{2}$ plays the role of metal-matrix alloy in the stage of powder preparation and consolidation by hot pressing, but after heating up to $\mathrm{T}_{\text {op }}$ metal is oxidized to spinel $\mathrm{CuMn}_{2} \mathrm{O}_{4}$ with dilatation effect. An increase in the plasticity of the matrix and the introduction of dilatation centers make it possible to controllably soften the conditions of hot pressing to $\sim 200 \mathrm{MPa}$ instead of $1 \mathrm{GPa}$, because the relative density of the cermet of $\sim 0.80$ will be quite sufficient.

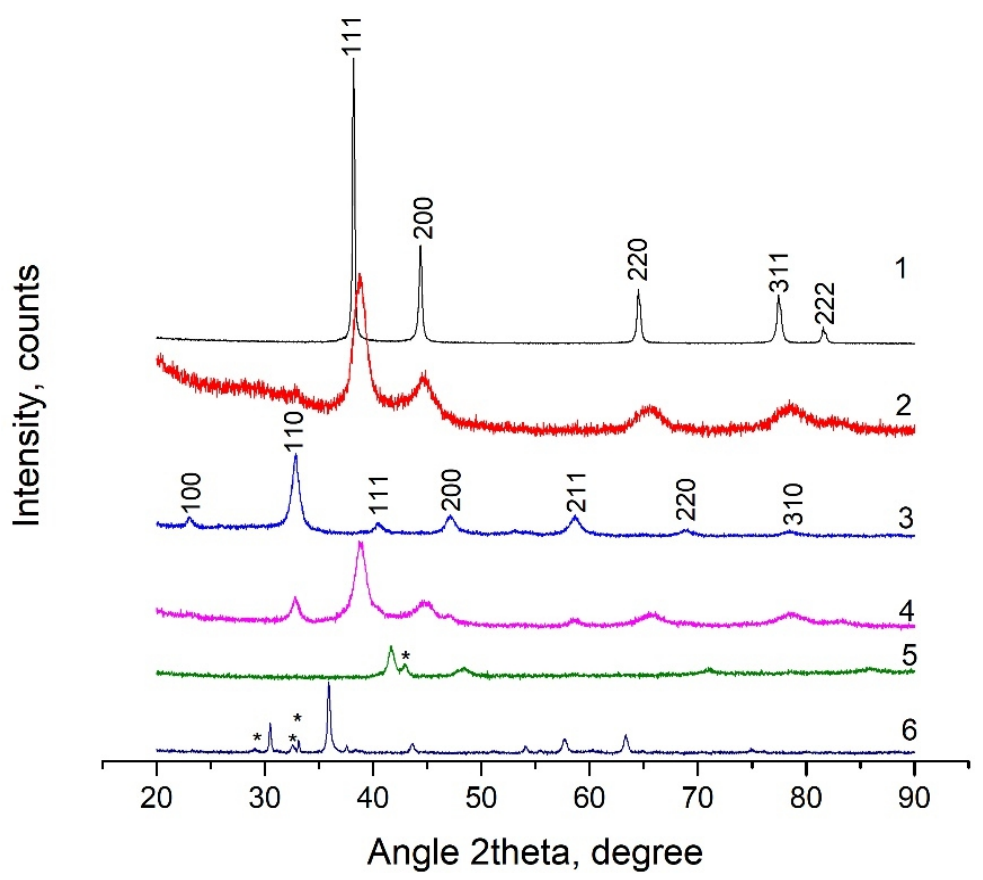

Fig. 2. Powder XRD patterns: $1-\mathrm{Ag}$ and 2- $\mathrm{Ag}_{0.7} \mathrm{Cu}_{0.3}, 10$ min $\mathrm{MA}$, size of crystallites $\mathrm{d}=11.3 \mathrm{~nm}$, with FCC structure, 3- P, 10 min MA (d=16.6 nm), 4- nanocomposite $\mathrm{Ag}_{0.7} \mathrm{Cu}_{0.7} @ 0.5 \mathrm{P}, 10$ min MA (for $\mathrm{Ag}, \mathrm{d}=11.1 \mathrm{~nm}$, for $\mathrm{P}, \mathrm{d}=16.6 \mathrm{~nm}$ ), 5- $\mathrm{CuMn}_{2}, 5$ min MA (FCC structure, peak * belongs to $\alpha-\mathrm{Mn}$ and grows upon mechanical activation), 6- sample 5 after oxidation at $750^{\circ} \mathrm{C}$, spinel structure, * belongs to low symmetry phase $\mathrm{CuMn}_{2} \mathrm{O}_{4}$.

The alloy $\mathrm{CuMn}_{2}$ and ceramics $\mathrm{CuMn}_{2} \mathrm{O}_{4}$ should have good wettability with silver due to high electronic conductivity, according to [4]. After oxidation of the alloy with the formation of nanoscale ceramic grains (Fig. 2), the silver matrix acquires a rigid framework that inhibits recrystallization and segregation. Moreover, spinel $\mathrm{CuMn}_{2} \mathrm{O}_{4}$ absorbs $\mathrm{CuO}$ after oxidation of $\mathrm{Cu}$ in $\mathrm{AgCu}$-alloy with a formation of more conducting ceramics $\mathrm{Cu}_{1.3} \mathrm{Mnn}_{1.7} \mathrm{O}_{4}$. The choice of $\mathrm{T}_{\text {op }}$ about $600{ }^{\circ} \mathrm{C}$ is associated with the long-term stability of modified metal support and the possibility of membrane regeneration by a short-term temperature rise to $650-700{ }^{\circ} \mathrm{C}$, at which disordering of oxygen vacancies in the fluorite structure can be expected. This operation will have little effect on the microstructure of nanocomposites and will prevent irreversible phase transformation of metastable fluorite into stable dielectric phases. In addition, heating up to 750-800 C completely eliminates dielectric phases. 
The acknowledgements. This work was supported by the Russian Foundation for Basic Research, Grant No. 20-03-00349, and within the framework of the state assignment of the Institute of Solid State Chemistry and Mechanochemistry, SB RAS FWUS-2021-0007.

\section{References}

1. C.S. Chen, A.J.J. Burggraaf, J. Appl. Electrochem. 29, 355 (1999)

2. V.V. Zyryanov, A.A. Matvienko, Inorgan. Mater. 51, 415 (2015)

3. S.V. Fedorov, A.S. Lysenkov, I.V. Kulbakin, 2020 IOP Conf. Ser.: Mater. Sci. Eng. 8480120191

4. V.V. Zyryanov, Materials Today: Proceedings 25, 416 (2020)

5. V.V. Zyryanov, Russian Chemical Reviews, 77, 105 (2008)

6. V.V. Zyryanov, S.A. Petrov, A.S. Ulihin, Ceram. Int. (to be published) 